\title{
Da assistência à docência: narrativas de médicos sobre os múltiplos caminhos que os tornaram preceptores
}

\section{From caring to teaching: physicians' accounts of the multiple paths which led them to become preceptors}

\author{
Luciana Muri Oliveira'1 ${ }^{10} \mid$ lucianamuri@gmail.com \\ Sandra Regina dos Santos Muri Oliveira ${ }^{2}$ (1) sandramurigmail.com \\ Maria da Conceição Vinciprova Fonseca' (1) concyvf@uol.com.br
}

\section{RESUMO}

Introdução: O internato de medicina é o estágio da formação em que o acadêmico põe em prática tudo o que aprendeu durante o ciclo básico, teórico. Nesse momento da graduação, os estudantes são supervisionados por profissionais médicos - os preceptores. Na maioria das vezes, esses preceptores se incorporam ao corpo docente da universidade por exercerem assistência profissional no local onde a prática ocorre, sem que haja capacitação ou orientação pedagógica prévia.

Objetivo: Este estudo teve como objetivo identificar os múltiplos caminhos que levam os médicos a atuar como preceptores do internato de medicina.

Método: Aplicou-se um questionário aos preceptores de Medicina, no qual uma pergunta aberta buscava, na narrativa desses sujeitos, entender como se efetivou o convite para a preceptoria.

Resultado: É possível observar como são múltiplos e dissonantes os caminhos que levam esses profissionais à docência.

Conclusão: Os resultados corroboram a importância de oferecer capacitação pedagógica adequada que valorize o preceptor de Medicina, profissional cuja atuação é central na formação dos futuros médicos.

Palavras-chave: Educação Médica; Medicina; Preceptor de Medicina.

\section{ABSTRACT}

Introduction: Medical Internship is stage of training at which the student doctor puts into practice everything that he or she has been taught in the theoretical part of the course. During this period of the undergraduate training, students are supervised by medical professionals - preceptors. These preceptors are usually brought into the university faculty based on the fact that they already work at the care setting where the practice takes place, with no prior training or pedagogical guidance.

Objective: This article aims to listen to professionals about how they became preceptors.

Method: A questionnaire was applied to medical preceptors consisting of a single, open-ended question, asking the respondent to give an account to explain how their invitation to become a preceptor came about.

Results: One can observe how the paths that lead these professionals to teaching are multiple and dissonant.

Conclusion: The results corroborate the importance of offering adequate pedagogical training that values this professional whose role is central to the training of future doctors.

Keywords: Medical Education; Medicine; Medical Preceptorship.

${ }^{1}$ Centro Universitário de Volta Redonda, Volta Redonda, Rio de Janeiro, Brasil.

${ }^{2}$ Hospital Geral de Nova Iguaçu, Nova Iguaçu, Rio de Janeiro, Brasil.

Editora-chefe: Daniela Chiesa

Editora associada: Daniela Chiesa

Recebido em 27/03/20; Aceito em 08/11/20.

Avaliado pelo processo de double blind review. 


\section{INTRODUÇÃO}

O curso de Medicina, segundo as novas Diretrizes Curriculares Nacionais (DCN), é constituído de 7.200 horas, das quais 35\%, aproximadamente 2.500 horas, são dedicadas à prática assistida, o chamado internato de medicina. Nesse período, os alunos ficam sob responsabilidade de tutores, os preceptores ${ }^{1}$.

O preceptor, que participa como docente no internato, na maioria das vezes, é um médico especialista ou não na determinada área em que atua que inicia a atividade de preceptoria sem nenhuma instrução pedagógica². Geralmente, é incorporado ao corpo de professores por ser médico assistente, em que a prática de estágio é inserida, sem que haja qualquer qualificação pedagógica para a atividade docente. Dessa forma, torna-se possível observar ainda um resquício do modelo apresentado por Abraham Flexner ${ }^{3}$.

O modelo flexneriano de 1910, vigente no Brasil desde a reforma universitária de 1968, traz como características perspectivas exclusivamente biológicas da doença, negação da determinação social da saúde, formação clínica exclusiva em hospitais e estímulo à disciplinaridade, em uma abordagem reducionista do conhecimento. No âmbito pedagógico, tal modelo é considerado massificador, passivo, hospitalocêntrico e tendente à superespecialização, com efeitos nocivos (e até perversos) sobre a formação do profissional de saúde. Ainda no que tange à prática em saúde, o modelo implica educação superior elitizada, resultando muitas vezes em profissionais despreparados à atenção em saúde básica ${ }^{4,5}$. Esse modelo de percepção do profissional precisava ser revisto, pois, apesar de mais de cem anos de sua publicação, permanece como referência até nossos dias. Assim, surgem em 2001 as novas DCN¹.

A visão atual da medicina necessita de diversas modificações e já vem sendo submetida a muitas, inclusive quanto ao profissional médico, desde sua formação. Entre as lacunas que necessitam ser revistas, a qualificação pedagógica do corpo docente certamente sobressai.

Atualmente a docência é considerada atividade secundária à profissão médica, e a atuação docente não é vista como profissão ou plano de carreira ${ }^{6}$. Assim, essa atuação, em especial no internato de medicina, muitas vezes se restringe à reprodução de modelos considerados válidos aprendidos anteriormente e à experiência prática cotidiana ${ }^{7}$. De acordo com o senso comum, a experiência docente é conquistada de forma natural, ou seja, na prática, e essa noção é largamente aceita pelos colegas de profissão, pois constitui-se num conceito generalizado sobre o que seja ensinar ${ }^{6}$.

Entretanto, o corpo docente é o alicerce da formação do profissional que será entregue à comunidade, e é sobre ele que devem ser construídas as bases das mudanças necessárias à formação de profissionais médicos ${ }^{8}$. Apenas recentemente os professores universitários e os preceptores do internato médico perceberam que a docência, como a pesquisa e a prática em qualquer profissão, demanda capacitação específica. Essa perspectiva encontra ressonância nos processos de implementação das DCN do curso de Medicina, as quais indicam a necessidade de mudar o foco da retenção/do acúmulo de informações para os movimentos de contextualização e generalização, de modo a buscar uma formação ética, crítica e humanista ${ }^{1,9}$.

Esta pesquisa foi realizada com objetivo de melhor conhecer os múltiplos caminhos que levaram o profissional médico de seu lócus tradicional - hospital, unidades básicas, consultório - à docência, como preceptor do internato de medicina, em uma universidade privada do Rio de Janeiro. Com isso, espera-se evidenciar a necessidade de preparação pedagógica dos docentes, com o propósito de enriquecer e potencializar a valorização desses profissionais, de modo que isso resulte, enfim, em melhor formação médica dos alunos.

\section{MÉTODO}

Este estudo é parte de uma dissertação apresentada ao Programa de Mestrado Profissional em Ensino em Ciências da Saúde e do Meio Ambiente do Centro Universitário de Volta Redonda (UniFOA), uma universidade privada do estado do Rio de Janeiro.

Realizou-se uma pesquisa de abordagem qualitativa, do tipo estudo de caso, com os sujeitos do ciclo profissional da graduação médica. Os dados foram obtidos na Faculdade de Medicina de uma universidade que constituiu o local da pesquisa, na cidade de Nova Iguaçu, no Rio de Janeiro. Atualmente, a universidade conta com 75 profissionais médicos que exercem função de preceptor, dos quais 53 atuam em um complexo hospitalar ligado à faculdade. A população estudada foi definida por adesão voluntária à investigação, ou seja, todos os preceptores participaram de forma espontânea. Na primeira etapa da pesquisa, os primeiros 33 questionários respondidos foram utilizados, o que equivale a $62,2 \%$ do total de profissionais que atuam intra-hospitalarmente.

Preservaram-se as identidade dos preceptores. Os questionários foram catalogados conforme ordem de recebimento, e utilizou-se a letra $\mathrm{P}$ seguida do número do questionário recebido.

Os critérios de inclusão foram: ser preceptor contratado da universidade onde a pesquisa foi realizada, atuar no complexo hospitalar que dá apoio à universidade e ter assinado oTermo de Consentimento Livre e Esclarecido (TCLE). Excluíramse aqueles que não assinaram o TCLE, não desejaram responder ao questionário ou não eram preceptores contratados pela instituição de ensino. 
Durante a pesquisa, aplicou-se um questionário com perguntas fechadas que visavam descrever o perfil do preceptor. Como essas perguntas não são o foco deste artigo, não serão mencionadas aqui.

No questionário, havia uma pergunta aberta, que o objeto do presentes estudos:

- Em algumas palavras, diga como aconteceu o convite para iniciar na preceptoria do internato de medicina desta universidade.

A partir da observação da diversidade nas repostas, deuse a elaboração deste artigo.

O projeto de pesquisa foi submetido ao Comitê de Ética em Pesquisa da Universidade Iguaçu (Unig), localizada no Rio de Janeiro, e aprovado em 10 de dezembro de 2019: Parecer $n^{\circ}$ 3.755.906 e Certificado de Apresentação para Apreciação Ética (CAAE) no 25647619.5.0000.8044. Após essa data e depois de os preceptores assinarem o TCLE, realizou-se a coleta de dados.

Como se efetuou uma avaliação qualitativa, os resultados obtidos não podem ser generalizados, o que representa um fator limitador deste estudo. Entretanto, sabe-se que a pesquisa qualitativa busca ser exemplar quanto ao tratamento de um dado problema, sendo adequada em situações em que não se pode esperar uma solução única e definitiva. Na questão de educação, esse é quase sempre o caso. O estudo é válido na medida em que investiga as narrativas dos sujeitos em um contexto de tempo e espaço, podendo assim ser útil a quem vive a situação.

\section{RESULTADOS}

$\mathrm{Na}$ primeira etapa da pesquisa, utilizaram-se 33 questionários, nos quais constam as narrativas dos preceptores da Faculdade de Medicina que descrevem como ocorreu o início deles na docência. Observaram-se múltiplas percepções dos preceptores sobre a função e o papel deles como instrumento de ensino. Para proteger a identidade das instituições, os nomes do hospital e da universidade foram substituídos, respectivamente, por $\mathrm{XX}$ e $\mathrm{XXX}$. A seguir, apresentam-se os recortes das respostas:

Fui convidado pelo chefe de serviço de clínica médica para realizar trabalho de preceptor. 0 mesmo conhecia meu trabalho com discentes pois eu havia sido residente do serviço de Clínica Médica e aluno aqui antes (P7).

Fui Residente do Hospital XX, 2007-2010, fui contratada pelo hospital em dezembro de 2009. Desde 2010, os alunos me acompanham no ambulatório (não era preceptora contratada). Após titulações, fui convidada pela chefia (P11).
Indicação da chefia por atuação na ginecologia e interesse em pesquisa científica (P13).

A especialidade em oncologia ortopédica me trouxe a preceptoria no Hospital XX (P14).

Após término da residência de infectologia na XXX, fui convidada para retornar para minha faculdade de origem para iniciar preceptoria em infectologia. Posteriormente também iniciei preceptoria em clínica médica (P16).

Sempre era chamada para responder pareceres em pacientes oncológicos. $E$, ao responder, sempre discutia com os alunos sobre o paciente e o caso. Fui vista como empática e com muito boa disposição para ensinar. Assim, fui convidada (P27).

Os recortes corroboram o fato de os preceptores serem, em sua maioria, convidados por conta da atuação profissional e das titulações, independentemente da capacitação pedagógica. $\mathrm{O}$ critério de contratação dos docentes nos cursos médicos é centrado na qualidade de seu desempenho em sua área técnica de atuação6.

Algumas respostas mostraram que o caminho para a preceptoria se deu muito pela comodidade de o profissional estar em um hospital-escola, e, assim, como já exercia de forma extraoficial o convívio com alunos, pois fora contratado pela universidade, houve apenas uma formalidade da atividade. As narrativas apresentadas a seguir ratificam os estudos avaliados anteriormente, em que se verifica a secundarização da atividade docente ${ }^{10}$ :

Fui convidada pela coordenação, sou ex-aluna da universidade $(P 2)$.

O convite aconteceu quando comecei a trabalhar no $X X(P 4)$.

Convite direto do Responsável do Setor de Clínica Médica (P8).

Por estar no XX há 10 anos na Emergência, fui convidada pelo Dr L. para ser preceptora (P10).

Aconteceu devido meu cargo de coordenação médica de Clínica Médica (P14).

Inicialmente trabalhava como visitador e após convite da chefia, me tornei preceptor (P19).

Fui convidada para complementar o quadro por maior disponibilidade de horário e pelo desejo de partilhar conhecimentos quando se tem troca com os alunos (P25).

Sendo Rotina do CTI, fui convidado pela minha chefe, que era professora, para ser preceptor (P29).

Em apenas um dos questionários respondidos, a capacitação para a docência foi citada como fator de escolha 
para exercer a preceptoria:

Iniciei meu trabalho como Médico Rotina do XX em 1998, ano em que a faculdade começou a utilizar as instalações do hospital como cenário da aprendizagem. Recebi o convite para ser preceptor em 1999, ano em que concluí meu curso de mestrado (P18).

Observou-se, em alguns recortes de respostas, que o convite se deu pelo desempenho do profissional perante alunos e pacientes:

Sempre tive interesse em exercer a docência na Medicina, desde a Residência aqui mesmo no XXjá me voluntariava a auxiliar os alunos no internato médico. Ao terminar a Residência e ser incorporada com staff do serviço, surgiu o convite e aceitei (P22).

Foi desafiador. Fiquei muito apreensiva, hoje em dia já está melhor. Me sinto desafiada todos os dias, em cada visita com os alunos. Me identifiquei muito com a preceptoria (P26).

Fui convidada para iniciar a preceptoria pela minha chefia, por gostar de passar conhecimento para os alunos (P30).

\section{DISCUSSÃO}

Durante o internato médico, momento em que o acadêmico é inserido na prática, o médico que assume a missão de ensinar está muitas vezes em sua primeira experiência com a docência. Como explicitado nos resultados, pode-se vislumbrar por meio dos relatos que são múltiplos e variados os caminhos que levam esse profissional médico da assistência à docência.

$\mathrm{Na}$ maioria dos casos, o critério de contratação dos docentes nos cursos de Medicina é centrado na qualidade de desempenho do médico em sua área técnica de atuação ${ }^{6}$. A maior parte dos recortes descritos corroboram o fato de os preceptores serem, em sua maioria, convidados em razão da atuação profissional e das titulações, independentemente da capacitação pedagógica.

Os participantes da pesquisa, ao refletirem sobre o início de prática do médico-preceptor e sobre como se estabeleceu práxis deles, referiram que a atividade se fez pelo fato de eles exercerem função no local da prática, sem considerações quanto à assistência aos alunos ou ao exercício da docência. Trata-se, na verdade, de uma formalização de uma atividade que já era exercida extraoficialmente sem que houvesse valorização dela ${ }^{10}$.

Quando se refere ao plano educacional, à escolha de teoria de aprendizagem ou à metodologia de ensino de preferência, o preceptor, quase sempre, se vê sem opções por falta de conhecimento sobre eles. Entretanto, sabemos que a escolha de abordagem do docente, os temas ou a forma de ensino e avaliação têm extrema importância, sendo necessário o conhecimento de conteúdos relevantes para que ele possa transitar confortavelmente em sua tarefa e facilitar a aprendizagem dos alunos. Não houve recorte que demonstrasse preocupação dos preceptores com esse aspecto, o que corrobora a importância da introdução à docência antes de exercê-la.

Segundo Chemello et al. ${ }^{11}$, a busca por preceptores capacitados para o ensino efetivo dos alunos é um problema iminente e preocupante. Vê-se a importância do preceptor de Medicina não somente para os alunos, mas também para a melhora da qualidade assistencial prestada aos pacientes.

De acordo com Oliveira et al. ${ }^{12}$, a preceptoria encontra sustentação na boa relação entre discentes e docentes. Contudo, são necessários esforços para a valorização dos profissionais que desempenham esse papel, uma vez que prática deles representa ganhos para o paciente e o ensino médico. Estudos mostram que, quando o médico, no exercício da função de preceptor, é acompanhado por uma equipe de acadêmicos, o paciente recebe uma assistência mais longa - 12 minutos a mais de atenção pela equipe médica, em comparação a quando $\mathrm{o}$ atendimento ocorre apenas entre o médico e o paciente ${ }^{11}$.

\section{CONCLUSÃO}

O processo de efetivação das mudanças sugeridas pelas novas DCN põe em relevo a necessidade de qualificação docente dos profissionais de saúde, tanto na graduação quanto na pós-graduação, sobretudo daqueles que atuam como preceptores em serviços dessa área ${ }^{1,13}$.

Quando o preceptor tem uma visão mais concreta a respeito da relevância de sua ação sobre a formação profissional do acadêmico de Medicina que por ele passa, isso é transformador. A preceptoria não pode ser vista como um adicional financeiro ao profissional já contratado onde a prática de internato está inserida.

Atualmente, o que se vê são preceptores incorporados à prática pedagógica sem qualificação como docente. Chegam a essa função por múltiplos e diferentes caminhos, sendo uns mais empenhados na assistência ao interno de Medicina e outros menos. Como não foram preparados, costumam ser reticentes a estratégias educacionais mais inovadoras, que buscam superar ou oferecer alternativas às práticas tradicionais de ensino.

No contexto universitário brasileiro, nas escolas de Medicina, a carreira do profissional docente é um processo que se dá sem acompanhamento institucional dos que iniciam essa atividade ${ }^{14}$.

Segundo Martinez ${ }^{15}$, não basta ao docente ter vocação para exercer a docência, ele precisa também ter competência, atitude, dedicação e conhecimento dos direitos e deveres éticos.

Sendo assim, as narrativas apresentadas aqui corroboram a conclusão de que a preceptoria no internato de medicina ainda é um instrumento de ensino a ser lapidado, uma vez que 
a forma de seleção, a visão dos próprios preceptores sobre o exercício acadêmico e a falta de capacitação pedagógica ainda precisam ser vistas com a seriedade que a tarefa merece. Assim se caminhará para atingir a formação ética, crítica e humanista descrita nas novas DCN para o curso de Medicina.

\section{CONTRIBUIÇÃO DAS AUTORAS}

Luciana Muri Oliveira elaborou o artigo. Sandra Regina dos Santos Muri Oliveira colaborou na produção do artigo e na aplicação dos questionários. Maria da Conceição Vinciprova Fonseca orientou a elaboração do artigo.

\section{CONFLITO DE INTERESSES}

As autoras declaram não haver conflito de interesses neste estudo.

\section{FINANCIAMENTO}

Declaramos que não houve financiamento para a realização desta pesquisa.

\section{REFERÊNCIAS}

1. Brasil. Resolução no 4, de 7 de novembro de 2001. Institui Diretrizes Curriculares Nacionais do Curso de Graduação em Medicina. Brasília: Ministério da Educação; 2001. Disponível em: http://portal.mec.gov.br/ cne/arquivos/pdf/CES04.pdf. ACESSO: 10 de dezembro de 2019.

2. Canuto AM, Batista SH. Concepções do processo ensino-aprendizagem: um estudo com professores de Medicina. Rev Bras Educ Med. 2009;33(4):624-32.
3. Ludmerer K. Understanding the Flexner Report. Acad Med. 2010;85:193-6.

4. Almeida Filho N. Reconhecer Flexner: inquérito sobre produção de mitos na educação médica no Brasil contemporâneo. Cad Saude Publica 2010;26(12):2234-49.

5. Flexner A. Medical education in the United States and Canada. New York: Carnegie Foundation for The Advancement of Teaching; 1910.

6. Costa N. Formação pedagógica de docentes de Medicina. Rev Latino-Am Enferm. 2010;18(1):102-8.

7. Batista NA, Souza SH. A função docente em medicina e a formação/ educação permanente do professor. Rev Bras Educ Med. 1998;22(3):31-6.

8. Lampert J. Tendências de mudanças na formação médica no Brasil: tipologia das escolas. São Paulo: Hucitec; 2002.

9. Masetto MT. Professor universitário: um profissional da educação na atividade docente. In: Masetto MT. Docência na universidade. Campinas: Papirus; 1998. p. 9-26.

10. Kjellgren Kl, Hendri G, Hultberg J, Plos K, Rydmark M, Tobin G, et al. Learning to learn and learning to teach - introductions to studies un higher education. Med Teach. 2008;30(8):239-45.

11. Chemello D, Manfrói WC, Machado CLB. O papel do preceptor no ensino médico e o modelo de preceptoria em um minuto. Rev Bras Educ Med. 2009;33(4):664-9.

12. Oliveira SF, Cunha AJLA, Trajman A, Teixeira C, Gomes MK, Halfoun V. Percepção sobre o internato de medicina da Universidade Federal do Rio de Janeiro pelos preceptores do serviço de atenção básica: um estudo de caso. Rev Bras Educ Med. 2017;41(1):79-85.

13. Vilela RB, Batista NA. Mestrado Profissional em Ensino na Saúde no Brasil: avanços e desafios a partir de políticas indutoras. Revista Brasileira de PósGraduação. 2015;12(28):15-25.

14. Costa NM, Cardoso CG, Costa DC. Concepções sobre o bom professor de medicina. Rev Bras Educ Med. 2012;36(4):499-505.

15. Martinez FL. Vacación docente versus profesión docente em las organizaciones educativas. Revista Eletrónica Interuniversitaria de Formación del Profesorado. 2010;13(4):43-51. 